\title{
System Quality, Information Quality, and Service Quality of Single Sign On (SSO) Information System at FISIP University of Diponegoro
}

\author{
Andi Wijayanto ${ }^{1}$, Primada Qurrota Ayun ${ }^{2}$ \\ \{andibilt@gmail.com ${ }^{1}$ \} \\ Universitas Diponegoro, Indonesia ${ }^{1,2}$
}

\begin{abstract}
This study aims to describe system quality, quality, information quality, and service quality in academic information systems through the implementation of Single Sign On (SSO) at the Faculty of Social and Political Sciences (FISIP), Diponegoro University. The research population is all SSO users at the Faculty of Social and Political Sciences (FISIP) Diponegoro University consisting of lecturers, educational staff and students. The sampling technique is carried out by purposive sampling with a sample size of 357 people. Methods of data collection using questionnaires, interviews, and documentation. The measurement scale uses a Liker scale. Data analysis using descriptive analysis. The results show that the system quality of the SSO Information System is quite good, but there are still aspects that need to be improved, especially the reliability aspect. The information system of SSO Diponegoro University has good quality information. The quality of SSO Services at Diponegoro University is considered quite good by its users. The study find several obstacles in implementing SSO.
\end{abstract}

Keywords: System Quality, Information Quality, Service Quality, Single Sign On

\section{Introduction}

The best service provided to agencies is to meet the expectations and needs of internal and external stakeholders in an educational institution, one of which is student affairs. This service is indispensable in a higher education institution in Indonesia that carries out the task of providing superior services to internal stakeholders who work in a university by providing motivation for employee morale, participation, work ethic, and responsibility so that productivity will increase in accordance with higher education goals, as a set of benchmarks for Student Services.

The existence of a quality standard consists of being used as a basis for measuring, determining the quality of service and the feasibility of serving the work unit in accordance with its programs to increase goodwill and trust in internal stakeholders. The emergence of the term excellent service can be said to be the best service in meeting customer expectations and needs. In other words, excellent service is a service that meets quality standards. Service that meets quality standards is a service in accordance with customer expectations and satisfaction. In this case the ability of educational institutions to provide services in accordance with the standards set to maximize stakeholder satisfaction.

One form of service made by Diponegoro University is SSO or Single Sign On which is an integrated system as a means of connecting the entire UNDIP academic community which 
is made with the aim of creating convenience for users in accessing available IT resources and facilities. The SSO system is expected to facilitate services in the field of student services and the academic system.

Some of the advantages of this SSO system are that it makes it easier for lecturers to see teaching schedules, easier for employees to arrange classes, and facilitate student presence. This system is expected to be able to provide transparency, accountability and equal rights. As explained by Sinambela et al. (2006), the quality of service is reflected in: (1) Transparency, namely services that are open, youthful and accessible to all parties who need them and are provided adequately and understood; (2) Accountability, that is, services can be accounted for in accordance with the provisions of laws and regulations; (3) Conditional, namely services in accordance with the conditions and capabilities of the service providers and recipients by adhering to the principles of efficiency and effectiveness; (4) Participatory, namely services that can encourage community participation by taking into account the aspirations, needs and expectations of the community; (5) Equal rights, namely services that do not discriminate from any aspect, especially ethnicity, race, religion, class, social status; (6) Balance of rights and obligations, namely services that consider aspects of justice between the provision and recipients of public services.

Unfortunately, the implementation is still constrained due to various factors. Related to this, Delone and Mclean [1] suggested that the successful implementation of an information system will depend on several factors, namely system quality, information quality and service quality. Good system quality, high quality of information, and excellent service quality will determine user satisfaction. Satisfaction of information system users will encourage the growing desire to continue to use information systems (intention to use). The expected final behavior of users is actual behavior in the form of continuous use of information systems so that it has an impact on the effectiveness and efficiency of the organization as a whole (net benefits).

This research is done to find out how good the system quality, information quality and service quality are related to the implementation of Single Sign On (SSO) in supporting academic and student activities at the Faculty of Social and Political Sciences, Diponegoro University.

In the information age, organizations in order to improve the efficiency and effectiveness of their operations are required to implement the use of information systems. An information system is a system in an organization that brings together the needs of daily transaction processing that supports the managerial operational functions of the organization with the strategic activities of an organization to be able to provide certain outsiders with the information needed for decision making [2].

Delone and Mclean [1] developed a model that explains the relationship of various factors that support the successful implementation of information systems in organizations. The model is shown in Figure 1. 


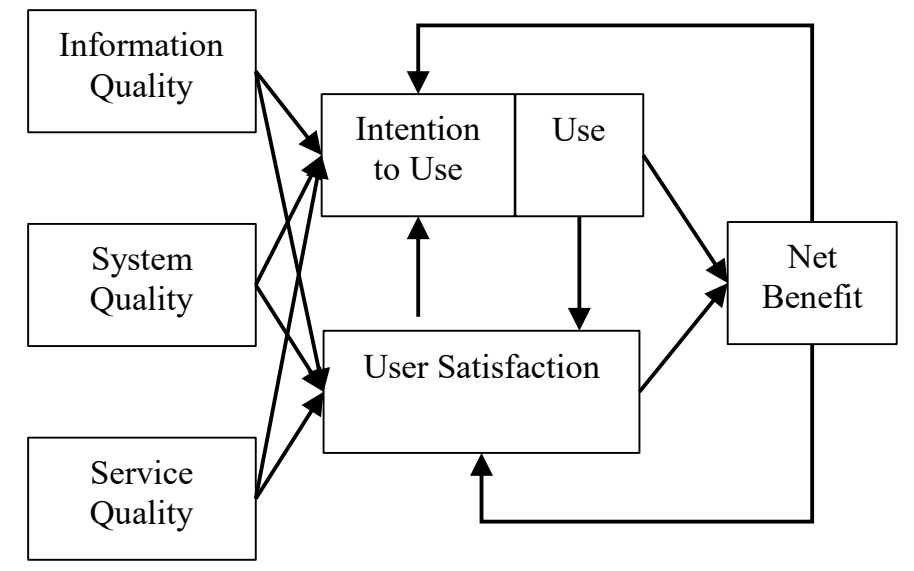

Fig. 1. D\&M Information Systems Success Model. Source: Delone and Mclean [1].

Delone and Mclean [1] suggest that the success of implementing an information system will depend on several factors, namely system quality, information quality and service quality. Good system quality, high quality of information, and excellent service quality will determine user satisfaction. Satisfaction of information system users will encourage the growing desire to continue to use information systems (intention to use). The expected final behavior of the user is actual use in the form of continuous use of information systems so that it has an impact on the effectiveness and efficiency of the organization as a whole (net benefits).

\section{Method}

This type of research is descriptive research. The research location is at the Faculty of Social and Political Sciences (FISIP), Diponegoro University, Semarang. The study population is all users of the SSO information system at the Faculty of Social and Political Sciences (FISIP) Diponegoro University, consisting of lecturers, educational staff and students. The sampling technique using purposive sampling. The sample criteria are status as lecturers, educational staff or students of FISIP Diponegoro University with an active status, have used SSO Diponegoro University, and are able and willing to fill out a questionnaire via Google form. Methods of data collection using questionnaires, interviews, and documentation. The measurement scale uses a 5-point Liker scale. Data analysis using descriptive analysis. Data processing uses the help of Microsoft Excel and SPSS for Windows software.

\section{Result and Discussion}

In general, the system quality of the SSO Information System has an average of 3.38 (5point Liker scale). This shows that students and education staff assess the system quality of 
the SSO Information System well and satisfactorily, but there are still aspects that need to be improved, especially the reliability aspect. The reliability aspect has the lowest average at 2.50 with the majority $(42.9 \%)$ of respondents choosing the bad category. This shows that the reliability aspect still needs to be improved and improved. Another aspect with the lowest average is the response time aspect, which is 3.22 , which means that the SSO Information System still has problems in its access speed. The usability aspect has the highest average of 3.95 which indicates that the respondents are satisfied with the usability of the SSO Information System. The level of satisfaction with the adaptability aspect is also quite high with an average of 3.69 which indicates that the SSO Information System can be easily changed according to the needs of its users, so that the SSO Information System can be further developed easily in improving and improving other aspects. The availability aspect also has a good average of 3.54, which indicates that respondents think that the SSO Information System is always available properly whenever needed.

Information quality is related to the content of the information system [1][3][4][5]. Information system content must be personalized, complete, relevant, easy to understand and secure. An information system is said to be complete if it can provide complete information according to user needs. The completeness of information can be affected by data. If the data that is owned is more complete, the information will be more complete. Completeness of information has several benefits, for example, it will speed up the readers of the information to make decisions. In this case, complete information must also be accompanied by valid data.

The average score for the quality of information is 3.82 , which means that respondents consisting of students and educational staff consider that the SSO information system at Diponegoro University has good quality information. Even so, there are several aspects that need to be improved so that the quality of information is better. The personalization aspect has the lowest score among other aspects in the quality of information, namely 3.72. Therefore, in terms of information quality, SSO must increase personalization by providing information in accordance with the wants and needs of its users. The security aspect also scores almost the same, which is 3.78. To improve the quality of security, the SSO information system must be able to maintain the confidentiality of quite a lot of important user data. Then, the highest score is the score on the easy-to-understand aspect, namely 3.95. This score shows that the SSO information system at Diponegoro University is easily understood by its users. The completeness of the completeness and the relevant aspects also had almost the same score, namely 3.81 and 3.82 respectively. This means that the respondents considered that the complete information systems available at SSO were complete likewise, with relevant aspects. Respondents gave responses that the relevance of the SSO Diponegoro University information system to the needs and desires of users is good.

Service quality is related to the overall support provided by service providers [1], in this case the FISIP of Diponegoro University. Service quality indicators used are responsiveness, assurance and empathy [6]. The tangible dimension is not used [7][8][9].

The guarantee aspect has the highest average at 3.60 with the majority $(47.1 \%)$ of respondents choosing the good category. This shows that the management of SSO Diponegoro University has good skills and knowledge in managing the SSO information system to ensure that its functions run smoothly. The level of satisfaction in the aspect of empathy is also quite high with an average score of 3.51, which means that the SSO manager of Diponegoro University can understand the difficulties faced by its users quite well. The aspect of responsiveness ranks last with an average number of 3.44, which indicates that the responsiveness of the SSO Diponegoro University managers to questions, reports or complaints from its users is considered quite well. Of the three categories, overall SSO 
Service Quality gets an average score of 3.52, which means that the SSO service quality of Diponegoro University is considered good enough by its users.

As a complex system built to meet the needs of multiple users, SSO is not a perfect system. There are still various obstacles faced in its implementation. Based on respondents' answers, these constraints can be grouped into several categories as follows:

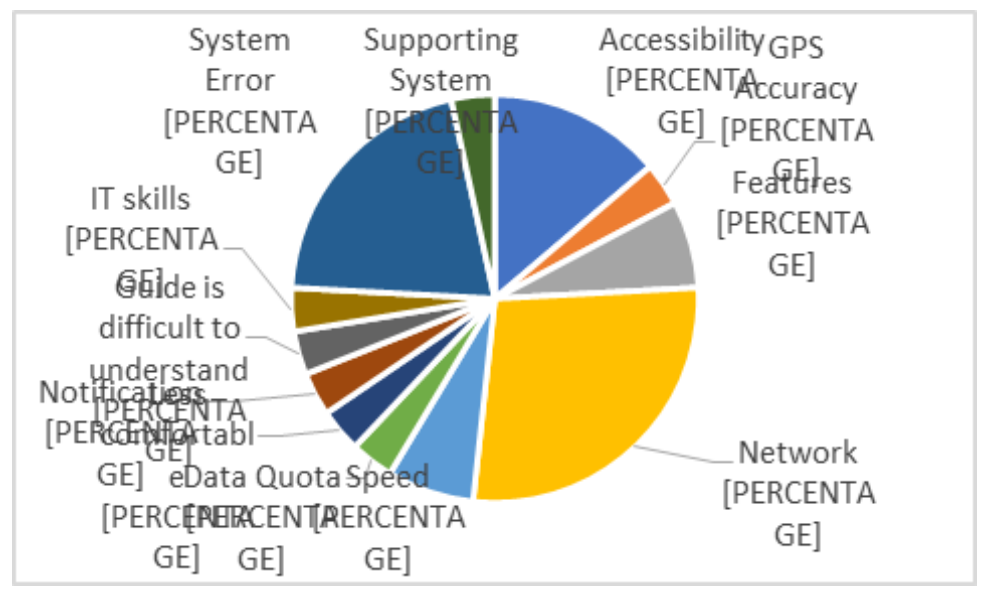

Fig. 2. Implementation Constraints.

The biggest obstacle encountered by many users is network constraints (28 present). This obstacle is related to the user's difficulties in being able to connect to SSO Diponegoro University because the internet network is weak, unstable or even non-existent. This happens because the access locations are scattered in various areas with varying network quality. The consequences of this can be very diverse. For lecturers, it can have an impact on absence from teaching, cannot open and reply to emails, cannot input grades, cannot process final assignment guidance, cannot access journals subscribed to by Diponegoro University, and cannot even do attendance. For students, network constraints can cause absenteeism from lectures, problems with academic registration, preparation of the IRS and access to KHS, not being able to see class schedules, lecturer schedules, and so on.

The next problem that is often faced is SSO often displays information that the system is having an error. As many as 21 presents of users conveyed these obstacles, especially during the early days of SSO implementation. This causes confusion to users because they cannot access SSO Diponegoro University.

Next up is the accessibility constraint. As many as 14 presents of users said that they faced problems when logging into SSO. Sometimes logging in is difficult and often fails. In this situation the user guesses whether it is caused by a network or system that is down.

Network speed problem is another obstacle faced by many SSO users of Diponegoro University. As many as 7 presents of SSO users complained that the loading speed of system pages often decreased. Complained access is often slow where the user does not know whether the slowdown in system speed is due to a bad connection or the system load is too heavy.

Other system components that become obstacles are some SSO features that the user cannot yet optimize for use. As many as 7 presents of SSO users complained about not being able to use the Online Lecture (Kulon) feature and the evaluation of the teaching and learning process (PBM) optimally. Kulon's features are considered too complicated so that it is difficult 
to learn and master by users. The Microsoft Teams application is considered to be easier and more interactive as an online learning medium. It is hoped that the Kulon feature can be simplified so that it makes it easier to use by SSO Diponegoro University users.

GPS accuracy is another obstacle raised by users. The use of GPS is a crucial factor for filling in the presence of lecturers where the presence of lecturers is considered valid if it is done consistently from their residence. GPS often misidentifies the location of the lecturer, especially if the attendance is done using a computer, either a PC or a laptop. This forces users to always fill their presence using a smartphone.

Another obstacle is the data quota. Using SSO requires an internet connection. Using SSO while on campus can take advantage of campus Wi-Fi access for free, while at home, users have to pay or buy a data quota in order to use SSO.

The use of SSO is also considered by users to be less comfortable. For example, to be able to access e-journals, users must log into SSO, then click on e-journal, choose an e-journal service provider, then carry out the search process by entering the desired keywords. These steps are considered too long when compared to searches for journal articles on other portals, such as Google Scholar. At Google Scholar, users only need to open Google Scholar and then enter the desired keywords and the results will come out immediately.

The next obstacle is the absence of notification of the latest information related to SSO services. This causes users to often miss important information in the fields of academia, human resources, and student affairs. Users must $\log$ in to SSO to be able to get updated information.

To help users master SSO, information system managers have provided user guides. Unfortunately, some users feel that the guides are still difficult to learn. As a result, trainings and mentoring are deemed necessary to improve SSO mastery by users.

On the other hand, some users also realize that their mastery of information technology is inadequate. The features in SSO are not optimally utilized by users because of their lack of mastery of information technology. This obstacle is especially often faced by users from the senior age group, whereas among juniors it is less common.

The final obstacle is the absence of a support system. SSO as a system is not a perfect system. The supporting subsystems sometimes don't work properly so that it can disrupt the whole system. In a condition where the system cannot run properly, there should be a support system that ensures that the business process continues. However, in the implementation of SSO, no support system has been developed to anticipate this possibility. For example, the attendance system is built to anticipate the failure of lecturers to fill work attendance if SSO is disrupted.

Of course, these various obstacles must be overcome to ensure that academic, administrative, and student service activities can run smoothly through the use of SSO. To improve the quality of internet connection, users must ensure the availability and stability of the existing networks in their respective places of residence. If necessary, changing the connection service provider can be done. On the other hand, SSO must be designed to be lightweight and reliable.

Furthermore, SSO technicians and admins must be able to better guarantee that this system is minimal or even zero error. System gaps should be identified as soon as possible and action taken to close the gaps. Early identification of system errors can be done not only by scanning the entire system, but also encouraging users to report system errors. Even though a helpdesk facility has been provided, its utilization by users is very lacking due to the user's ignorance of this feature. 
SSO Diponegoro University has tens of thousands of users. Simultaneous access sometimes burdens the system so that the login process to SSO becomes difficult. It is necessary to increase the capacity or larger bandwidth so that it does not interfere with simultaneous system usage. In addition, the increased capacity will also support increased access speed to SSO.

SSO continues to be developed. New SSO features are added to accommodate various user needs. However, updates and additional features must also be accompanied by socialization and training on how to use them. Through this, users will be able to optimize their utilization.

With regard to GPS accuracy constraints, the accuracy of identifying the user's location via a computer or laptop is indeed lower than a smartphone. Therefore, users should still use smartphones for presence.

Many students face financial constraints in purchasing internet data quotas. Therefore, the assistance that has been provided by Diponegoro University is a pretty good solution in overcoming these obstacles.

The next obstacle is the absence of the latest information notifications related to SSO services. SSO managers should design a system that can send notifications to users, both the mobile version (android or IOS) and the web version. Thus, users will not miss the latest information provided by SSO.

Training and mentoring needs to be done especially if SSO adds new features this is because some users have difficulty mastering SSO features just by reading the user manual. Others feel that they lack mastery of information and communication technology, so they need to be trained and assisted to ensure that they can use SSO features properly.

Finally, there is a need for a support system other than SSO. In a condition where the SSO system cannot run properly, the existence of a support system will ensure that the service process continues. The support system can be online or offline. In situations where offline systems are not possible, online support systems will play an important role.

\section{Conclusions}

The system quality of the SSO Information System is good enough, however there are still aspects that need to be improved, especially the reliability aspect. The information system of SSO Diponegoro University also has good quality information. Even so, there are several aspects that need to be improved so that the quality of information is getting better, namely the personalization aspect has the lowest score among other aspects in the quality of information. Overall, the service quality of SSO Diponegoro University is considered quite well by its users. The obstacles encountered by SSO Diponegoro University users are network constraints, SSO often displays information that the system is in error, accessibility constraints, network speed, lack of optimization of SSO feature usage by users, GPS accuracy constraints for lecturer presence, data quota, less comfortable to use, no notification of the latest information related to SSO services, insufficient mastery of information technology, and no support system.

To improve the quality of internet connection, users must ensure the availability and stability of the existing networks in their respective places of residence. On the other hand, SSO must be designed to be lightweight and reliable. SSO technicians and admins must be able to better guarantee that this system is minimal or even zero error. System gaps should be identified as soon as possible and action taken to close the gaps. It is necessary to increase the 
capacity or larger bandwidth so that it does not interfere with simultaneous system usage. SSO must continue to be developed to accommodate various user needs. However, it must also be accompanied by socialization and training on how to use it. SSO managers should design a system that can send notifications to users, both the mobile version (android or IOS) and the web version. Thus, users will not miss the latest information provided by SSO.

\section{References}

[1] W. H. Delone and E. R. McLean, "The DeLone and McLean model of information systems success: a ten-year update," J. Manag. Inf. Syst., vol. 19, no. 4, pp. 9-30, 2003.

[2] H. Antonio and N. Safriadi, "Rancang Bangun Sistem Informasi Administrasi Informatika (SIADIF)," J. ELKHA, vol. 4, no. 2, 2012.

[3] W. J. Doll, W. Xia, and G. Torkzadeh, "A confirmatory factor analysis of the end-user computing satisfaction instrument," MIS Q., pp. 453-461, 1994.

[4] A. Rai, S. S. Lang, and R. B. Welker, "Assessing the validity of IS success models: An empirical test and theoretical analysis," Inf. Syst. Res., vol. 13, no. 1, pp. 50-69, 2002.

[5] L. T. Utomo, Y. T. Ardianto, and N. Sisharini, "Pengaruh kualitas sistem, kualitas informasi, kualitas layanan, terhadap kepuasan pengguna sistem informasi akademik universitas merdeka malang," J. Teknol. dan Manaj. Inform., vol. 3, no. 2, 2017.

[6] A. Parasuraman, L. L. Berry, and V. A. Zeithaml, "More on improving service quality measurement," J. Retail., vol. 69, no. 1, pp. 140-147, 1993.

[7] C. L. Carr, "A psychometric evaluation of the expectations, perceptions, and difference-scores generated by the IS-adapted SERVQUAL instrument," Decis. Sci., vol. 33, no. 2, pp. 281-296, 2002.

[8] J. Page, "How to launch data governance initiative," Bus. Intell. J., vol. 16, no. 2, pp. 17-25, 2011.

[9] W. J. Kettinger and C. C. Lee, "Pragmatic perspectives on the measurement of information systems service quality. MIS Q. 21 (2), 223-240 (1997).”. 